\title{
Numerical modelling of suffusion by discrete element method: a new internal stability criterion based on mechanical behaviour of eroded soil
}

\author{
Nadjibou Abdoulaye Hama ${ }^{1}$, Tariq Ouahbi ${ }^{*}$, Said Taibi ${ }^{1}$, Hanène Souli ${ }^{2}$, Jean-Marie Fleureau ${ }^{3}$ and Anne Pantet $^{1}$ \\ ${ }^{1}$ Normandie Univ, Unihavre, UMR 6294 CNRS, LOMC, 76600 le Havre, France \\ ${ }^{2}$ UMR CNRS 8579, LTDS, Ecole Nationale d'Ingénieurs de Saint Etienne, France \\ ${ }^{3}$ UMR CNRS, Laboratoire MSS-Mat, CentraleSupélec, France
}

\begin{abstract}
Non-cohesive soils subjected to a flow may have a behavior in which fine particles migrate through the interstices of the solid skeleton formed by the large particles. This phenomenon is termed internal instability, internal erosion or suffusion, and can occur both in natural soil deposits and also in geotechnical structures such as dams, dikes or barrages. Internal instability of a granular material is its inability to prevent the loss of its fine particles under flow effect. It is geometrically possible if the fine particles can migrate through the pores of the coarse soil matrix and results in a change in its mechanical properties. In this work, we uses the three-dimensional Particle Flow Code (PFC3D/DEM) to study the stability/instability of granular materials and their mechanical behavior. Kenney and Lau criterion sets a safe boundary for engineering design. However, it tends to identify stable soils as unstable ones. The effects of instability and erosion, simulated by clipping fine particles from the grading distribution, on the mechanical behaviour of glass ball samples were analysed. The mechanical properties of eroded samples, in which erosion is simulated and gives a new approach for internal stability. A proposal for a new internal stability criterion is established, it is deduced from the analysis of relations between the mechanical behaviour and internal stability, including material contractance.
\end{abstract}

\section{Introduction}

The construction of earth structures such as dams, levees and road embankments often requires the use of granular soils. These cohesionless granular media are often composed of two parts: a solid (coarse) skeleton that can support and transmit the external stresses, and fine particles that can move through the constrictions. These granular soils can be internally stable or unstable, and more or less resistant to the phenomena of internal erosion and suffusion. These phenomena caused by seepage of water through the material affect its mechanical behaviour and may lead to its collapse.

In granular soils, suffusion may occur only when these three following conditions are satisfied: the fine particles are smaller than the size of constrictions formed by the coarse particles; fine particles do not fill the constrictions and are free to move; the hydraulic gradient is high enough. Kenney and Lau [1-2] proposed a criterion to assess the internal stability of granular media. This criterion is based on the assumption that each class of grain, characterized by its diameter $\mathrm{d}$ must be prevented to move by the grains whose diameter is comprised between $\mathrm{d}$ and $4 \mathrm{~d}$.

This criterion consists in plotting the PSD curve of a soil in a diagram with the mass fraction $\mathrm{F}$ of particles whose diameter is smaller than $\mathrm{d}$ on the $\mathrm{X}$-axis and the mass fraction $\mathrm{H}$ of the particles whose diameter is comprised between $\mathrm{d}$ and $4 \mathrm{~d}$ on the $\mathrm{Y}$-axis. The soil is considered as stable if, for $\mathrm{F}<20$ or $30 \%$, the curve obtained is located below the line $\mathrm{H}=\mathrm{F}$. Otherwise, if some portion of this curve passes above the line $\mathrm{H}=\mathrm{F}$, the soil is considered as unstable. According to Kenney and Lau [1-2], F values of $20 \%$ apply to the soils with widely graded primary fabric $(\mathrm{Cu}>3)$ and the value of $30 \%$ to the soils with narrowly graded primary fabric $(\mathrm{Cu}<3)$. The mechanism of internal stability has also been widely studied by other authors [3-9], mainly in order to define criteria for soils likely to develop internal erosion.

Kézdi [4] proposed a criterion to assess the internal stability of soil based on the division of the grain size distribution curve into its coarser and finer components. Each component must satisfy the criterion D'15 / D' 85 $=4$ [5], where D' 15 is the particle diameter of the filter corresponding to $15 \%$ of passing and D' 85 is the particle diameter of the soil to be protected, corresponding to $85 \%$ of passing.

A unified approach combining the methods of Kézdi [4] and Kenney and Lau [1-2] was established by $\mathrm{Li}$ and Fannin [6]. The common feature of both methods is the examination of the slope of the gradation curve over a

\footnotetext{
Corresponding author: tariq.ouahbi@univ-lehavre.fr
} 
discrete interval of its length. This approach yielded a more reliable estimation of soil stability [7].

Internal instability has also been assessed by Andrianatrehina et al. [8]. The stability of nine samples with different grain size distribution curves, derived from direct grain size measurements carried out after triaxial and vibration tests was studied. The results were compared with the predictions of several methods $[1,4$, $5,9,10]$.

In the literature, many works have focused on the evaluation of the internal stability of materials, but few of them studied the change in the mechanical behaviour resulting from grain size distribution changes after flow. The objective of this work is to establish a relationship between the internal stability parameters and the mechanical behaviour of materials. To achieve this, a Discrete Elements Method (DEM) is used to model soil sample submitted to a triaxial paths. A new criterion of internal stability taking into account the mechanical behaviour of soils is proposed.

\section{Numerical modelling}

This numerical study was performed with PFC 3D that uses the discrete element method (DEM) originally developed by Cundall and Strack [11, 12]. The DEM method is very suitable for numerical modelling of granular systems behaviour (granular soils; rocks...).

Materials are discretized in elements of simple shape (spheres) that interact with neighbouring contact elements.

A material is generated with a target granular distribution and porosity and then subjected to a triaxial test. Three stages were employed for the numerical specimen tests: (1) specimen preparation; consolidation and (3) specimen shearing.

\subsection{Numerical sample generation}

The generation procedure of granular sample with a given grain size distribution curve and a given porosity developed by Abdoulaye Hama et al $[13,14]$ is used.

\subsection{Triaxial modelling}

The triaxial test in PFC3D is performed by confining a cylindrical sample within three walls. The top and the bottom walls simulate loading platens and the lateral one simulates the confining pressure experienced by the sample sides. The void volume can be calculated using the total volume of the sample minus the total volume of the solid particles.

The axial strain can be calculated by the following equation (which can be obtained by a combination of the Eulerian and Lagrangian strains):

$$
\varepsilon=\frac{H_{1}-H_{0}}{\frac{1}{2}\left(\mathrm{H}_{1}+H_{0}\right)}
$$

Where $\mathrm{H} 0$ is the initial height of the sample and $\mathrm{H} 1$ is the current height during the test.
The tridimensional particle flow determines the wall stress and adjusts the wall velocity to reduce the difference between the current wall stress and the target wall stress $\sigma^{\mathrm{w}}, \sigma^{\mathrm{t}}$. The wall velocity $\dot{\mathrm{u}}^{\mathrm{w}}$ must satisfy:

$\dot{\mathrm{u}}^{\mathrm{w}}=\mathrm{G}\left(\sigma^{\mathrm{W}}-\sigma^{\mathrm{t}}\right)=\mathrm{G} \Delta \sigma$

Where $\mathrm{G}$ is the "gain" parameter that is estimated by:

$G=\frac{\alpha A}{k_{n}^{w} \Delta t}$

\section{Results and discussion}

When it occurs in a soil sample the phenomenon of suffusion, its PSD changes and this affects its internal stability. To study the impacts of suffusion on the mechanical behaviour of granular soils, five PSD identified by S1; S2; S3; S4 and S5 were defined from an alluvial deposit from the Rhône River in France [14]. Table 1 summarises the Characteristics of these samples.

Table 1: Characteristics of different samples

\begin{tabular}{|c|c|c|c|c|c|}
\hline Material & S1 & S2 & S3 & S4 & S5 \\
\hline D10 (mm) & 0.56 & 1.01 & 1.26 & 1.29 & 7.61 \\
\hline $\mathrm{D} 30(\mathrm{~mm})$ & 1.62 & 2.31 & 3.52 & 2.50 & 6.5 \\
\hline $\mathrm{D} 50(\mathrm{~mm})$ & 2.70 & 8.00 & 5.87 & 7.61 & 8.00 \\
\hline $\mathrm{D} 60(\mathrm{~mm})$ & 3.25 & 6.15 & 5.85 & 6.20 & 6.3 \\
\hline $\mathrm{CU}=\mathrm{d} 60 / \mathrm{d} 10$ & 5.8 & 6.08 & 4.64 & 4.80 & 0.82 \\
\hline $\mathrm{CC}=\mathrm{d} 30 / \mathrm{d} 60 * \mathrm{~d} 10$ & 0.89 & 0.37 & 0.47 & 0.31 & 0.13 \\
\hline $\begin{array}{c}\text { Porosity n (\%) } \\
\text { Minimum ratio of } \\
\text { stability (H/F) min }\end{array}$ & 1.85 & 2.47 & 3.87 & 3.38 & 0 \\
\hline $\begin{array}{c}\text { Maximum } \\
\text { coefficient of } \\
\text { retention (D }\end{array}$ & 15.5 & 1.95 & 2.20 & 2.31 & 3.24 \\
\begin{tabular}{c} 
d85) max. \\
\hline
\end{tabular} & & & & 40 & 40 \\
\hline
\end{tabular}

Table 1 shows that the only differences between samples are geometric. Samples PSD are all widely graded $(\mathrm{Cu}>3)$ with slight curvature. They have different minimum stability index and different maximum retention coefficient. We interpret this as a consequence of the phenomenon of suffusion. If it occurs, it causes loss or gain of particles. From the internal stability parameters $\left((\mathrm{H} / \mathrm{F})_{\min }\left(\mathrm{D}_{15} / \mathrm{d}_{85}\right)_{\text {max }}\right)$ the samples are classified according to the Kenney and Lau and Kezdi criteria. Samples internal stability state is presented on Table 2. One can note that the two criteria diverge on samples S1 and S5. 
Table 2: Samples classification according to the Kenney and Lau and Kezdi criteria

\begin{tabular}{|c|c|c|c|c|c|}
\hline Material & S1 & S2 & S3 & S4 & S5 \\
\hline Kenney \& Lau (985-1986) & S & S & S & S & U \\
\hline Kezdi (1979) & U & S & S & S & S \\
\hline \multicolumn{7}{|c|}{ S stands for "Stable" and U for "Unstable" } \\
\hline
\end{tabular}

\subsection{Triaxial results}

Each sample was subjected to a consolidated and drained triaxial test simulation, at same initial void ratio of $\mathrm{e}=0.66$ and constant confining stress $\sigma_{3}=200 \mathrm{kPa}$. Results are presented in the deviatoric $\left(\varepsilon_{1} ; \mathrm{q} / \mathrm{p}\right)$ and the volume change $\left(\varepsilon_{1}, \varepsilon_{\mathrm{v}}\right)$ planes (Fig 1). They are used to calculate the stress ratio $(\mathrm{q} / \mathrm{p})_{\max }$ and the maximum contractancy $\left(\varepsilon_{\mathrm{vmax}}\right)$ corresponding at projection of the characteristic point in the $\left(\varepsilon_{1} ; \mathrm{q} / \mathrm{p}\right)$ plane.

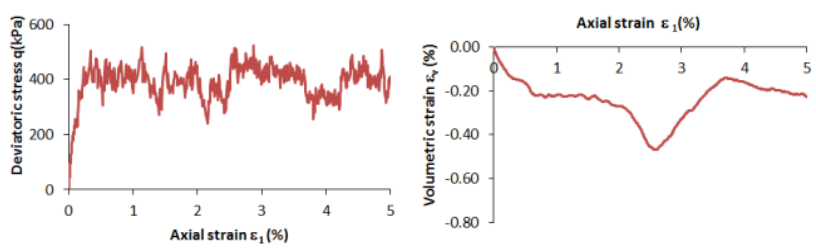

$\mathrm{S} 1:(\mathrm{H} / \mathrm{F})_{\min }=1.85 ;\left(\mathrm{D}_{15} / \mathrm{d}_{85}\right)_{\max }=15.5$
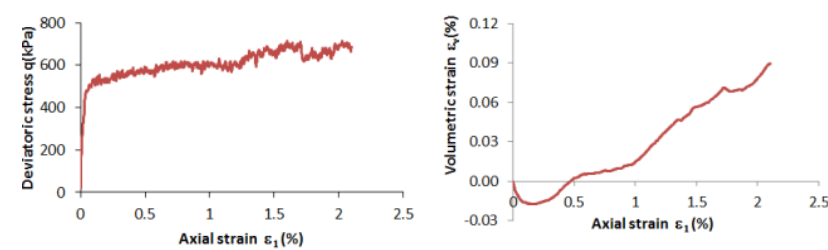

$\mathrm{S} 2:(\mathrm{H} / \mathrm{F})_{\min }=2.47 ;\left(\mathrm{D}_{15} / \mathrm{d}_{85}\right)_{\max }=1.95$
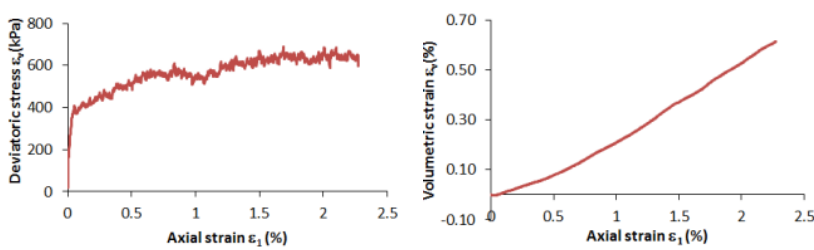

$\mathrm{S} 3:(\mathrm{H} / \mathrm{F})_{\min }=3.87 ;\left(\mathrm{D}_{15} / \mathrm{d}_{85}\right)_{\max }=2.20$
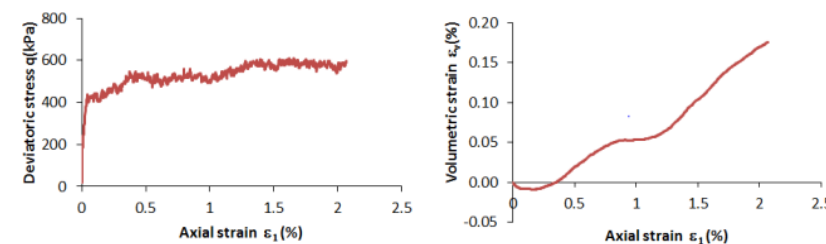

$\mathrm{S} 4:(\mathrm{H} / \mathrm{F})_{\min }=3.38 ;\left(\mathrm{D}_{15} / \mathrm{d}_{85}\right)_{\max }=2.31$
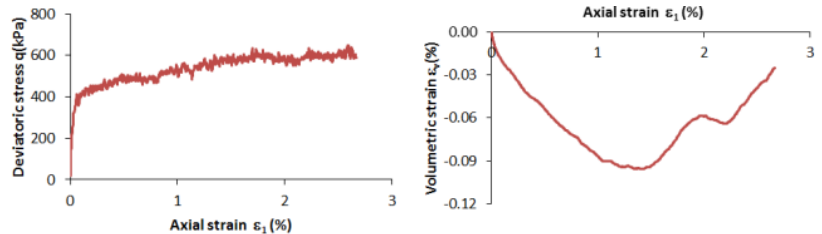

$\mathrm{S} 5:(\mathrm{H} / \mathrm{F})_{\min }=0 ;\left(\mathrm{D}_{15} / \mathrm{d}_{85}\right)_{\max }=3.24$

Fig 1: Triaxial results

Despite the identical test conditions, samples exhibit different maximum shear strength and different maximum contractancy (Fig 1). Table 3 showed a comparison between mechanical parameters $(\mathrm{q} / \mathrm{p})_{\max }$ and $\left.\varepsilon_{\mathrm{vmax}}\right)$ and internal stability ones $\left((\mathrm{H} / \mathrm{F})_{\min }\left(\mathrm{D}_{15} /\right.\right.$ d85) max.).

Table 3: Comparison of mechanical and internal stability parameters

\begin{tabular}{|c|c|c|c|c|c|}
\hline Material & S1 & S2 & S3 & S4 & S5 \\
\hline$(\mathrm{H} / \mathrm{F})_{\min }$ & 1.85 & 2.47 & 3.87 & 3.38 & 0 \\
\hline$\left(\mathrm{D}_{15} / \mathrm{d}_{85}\right)_{\max } \cdot$ & 15.5 & 1.95 & 2.20 & 2.31 & 3.24 \\
\hline$(\mathrm{q} / \mathrm{p})_{\max }$ & 1.42 & 1.6 & 1.6 & 1.51 & 1.4 \\
\hline$\varepsilon_{\mathrm{vmax}}(\%)$ & 0.5 & 0.02 & 0 & 0.01 & 0.9 \\
\hline
\end{tabular}

It is noted that the parameters of internal stability influence the mechanical behaviour of soil samples (Table 3). Samples with higher deviatoric stress and lower contractancy present a minimum ratio of stability higher than their maximum coefficient of retention: $(\mathrm{H} / \mathrm{F})_{\min }>\left(\mathrm{D}_{15} / \mathrm{d}_{85}\right)_{\max }$.

\subsection{Proposition of a new stability criterion}

Internal instability of a granular material is its inability to prevent the loss of its fine particles under flow effect. It is geometrically possible if the fine particles can migrate through the pores of the coarse soil matrix and results in a change in its mechanical properties.

From relationship $(\mathrm{H} / \mathrm{F})_{\min }>\left(\mathrm{D}_{15} / \mathrm{d}_{85}\right)_{\max }$, we propose a new criterion for assessing soil internal stability. It takes account mechanical behaviour and classifies stable sample with $\mathrm{H} / \mathrm{F}>\mathrm{D} 15 / \mathrm{d} 85$. Fig 2 shows the classification of our samples according the proposed criterion. Samples S2, S3 and S4 are stable and S1 and S5 are unstable. 


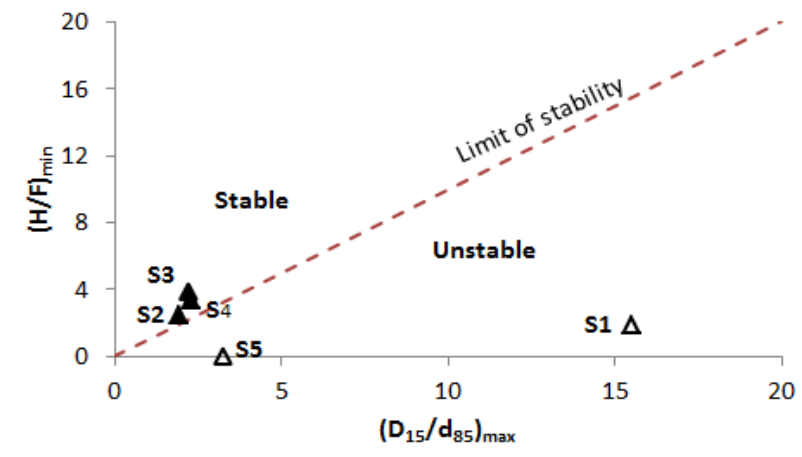

Fig 2: Proposed criterion

\section{Validation of proposed criterion}

To validate our criterion, 16 samples were taken from literature results: 4 from Kenney and Lau [3], 8 from Andrianatrehina et al [8], and 4 from Indraratna et al [10]. The choice of these samples is motivated by the diversity of their density and that of the analysis method of the authors. These 16 samples are classified using the proposed criterion. Fig 3 presents this classification and compares it with experimental result.

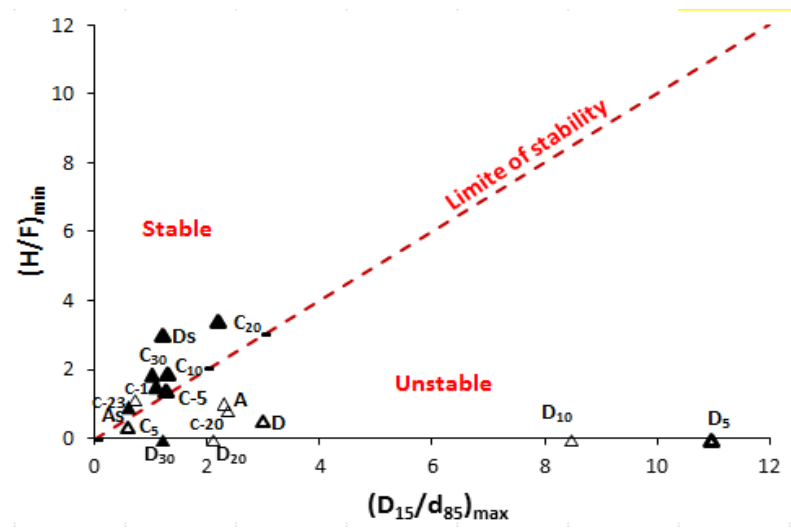

Fig 3: Validation of proposed criterion with literature results. 'Hollow triangle' means experimentally unstable 'Full triangle' means experimentally stable

\section{Conclusions}

Discrete elements method is used to model sand samples and to simulate their mechanical behaviour on triaxial paths. Consolidated and drained triaxial test simulation carried out at same initial void ratio and confinement stress. The maximum values of contractancy in $\left(\varepsilon_{1} ; \varepsilon_{\mathrm{V}}\right)$ plane and the maximum deviatoric stress in the $\left(\varepsilon_{1} ; \mathrm{q} / \mathrm{p}\right)$ planee have been determined for each sample. Results showed that mechanical behaviour of granular material is influenced by the stability parameters $(\mathrm{H} / \mathrm{F})_{\min }$ and $\left(D_{15} / d_{85}\right)_{\text {max }}$. Effects of suffusion on soil mechanical behaviour was analysed and a new internal stability criterion was proposed. Contrary to classical criteria, it takes into account the mechanical behaviour of the soil. It classifies as stable particle sizes distribution with $\frac{\mathrm{H}}{\mathrm{F}} \geq \frac{\mathrm{D}_{15}}{\mathrm{~d}_{85}}$, corresponding to the better mechanical behaviour.

\section{Acknowledgement}

This work was supported by EOLIFT project financed by ADEME.

\section{References}

1. T.C. Kenney, D. Lau (1986) Internal stability of granular filters: reply. Canadian Geotechnical Journal; 23: 420 - 423.

2. T.C. Kenney, D. Lau (1985) Internal stability of granular filters. Canadian Geotechnical Journal; 22 $: 215-225$.

3. J. Lafleur, J. Mlynarek, A. Rolin (1989) Filtration of broadly graded cohesionless soils. Journal of Geotechnical Engineering 1989; 115 (12):1747 1768.

4. A. Kézdi (1979) Soil Physics - Selected Topics. Elsevier Scientific Publishing Co: Amsterdam.

5. T. Shire and C. O'Sullivan (2012). Micromechanical assessment of an internal stability criterion. Acta Geotechnica, 8(1), 81-90.

6. M. Li, and R.J. Fannin (2008) Comparison of two criteria for internal stability of granular soil. Can. Geotech. J., 45(9), 1303 - 1309.

7. V.F. De Mello (1975) Some lessons from unsuspected, real and fictitious problems in earth dam engineering in Brazil. In Proceedings 6th Regional Soil Mechanics and Foundation Engineering Conference for Afrika. p. 285-304.

8. L. Andrianatrehina, H. Souli, J.J. Fry , Q.T. Phan, J.M. Fleureau (2012) Internal stability of granular materials in triaxial tests. ICSE Paris

9. USACE (U.S. Army Corps of Engineers) (1953) Investigation of filter requirements for underdrains. Tech. Memo. No. 3-360, U.S. Waterways Experiment Station, Vicksburg, MI.

10. B. Indraratna, J. Israr and C. Rujikiatkamjorn (2015) Geometrical Method for Evaluating the Internal Instability of Granular Filters Based on Constriction Size Distribution. Journal of Geotechnical and Geoenvironmental Engineering,141(10), 04015045.

11. P.A. Cundall, O.D.L. Strack (1979) The Distinct Element Method as a Tool for Research in Granular Media, Part II. University of Minnesota: Minnesota.

12. P.A. Cundall, O.D.L. Strack (1979) Discrete numerical model for granular assemblies. Geotechnique 1979; 29 (1):47 - 65.

13. N. Abdoulaye Hama, T. Ouahbi, S. Taibi, S. Souli, J.M. Fleureau, A. Pantet. Analysis of mechanical behaviour and internal stability of granular materials using discrete element method. Int. Int. J. Numer. Anal. Meth. Geomech. (2016); 40:1712-1729. DOI: 10.1002/nag.2510.

14. N. Abdoulaye Hama, T. Ouahbi, S. Taibi, J.M. Fleureau, A. Pantet, S. Souli, (2014). Numerical Analysis of Internal Stability of Granular Materials using Discrete Element Method. Geomechanics from Micro to Macro, CRC Press (2014). DOI : 10.1201/b17395-94. 